\title{
Design Optimization of Permanent Magnet Clutch with Ārtap Framework
}

\author{
Ekaterina Andriushchenko ${ }^{1 *}$, Jan Kaska², Ants Kallaste1, Anouar Belahcen³, Toomas Vaimann, \\ Anton Rassõlkin ${ }^{1}$
}

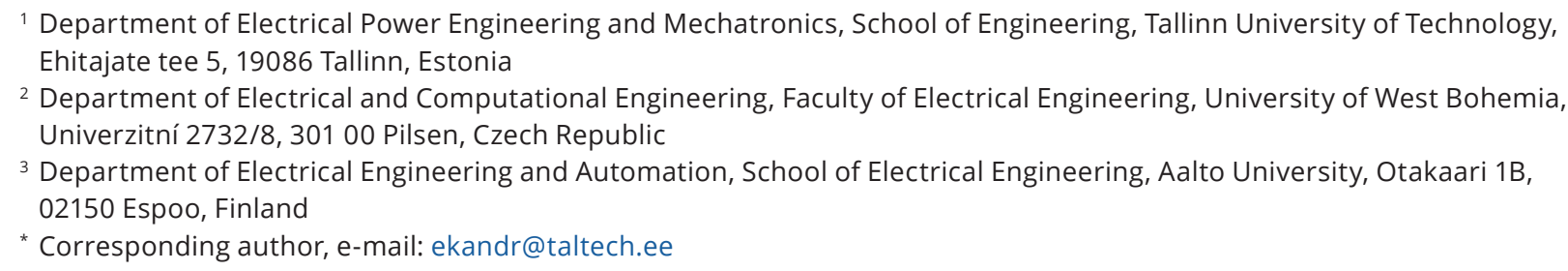

Received: 09 August 2020, Accepted: 14 September 2020, Published online: 09 March 2021

\begin{abstract}
So far, Permanent Magnet (PM) clutches have been broadly used as torque transmission devices. With the aim of effective utilization of materials and energy in the manufacturing of PM clutches, design optimization has been widely applied. Generally, PM clutches are optimized applying linear dimensions as optimization parameters. On the contrary, optimization of PM clutch shapes has not been done extensively. Therefore, this paper performs optimization of PM clutch shapes with the following objectives: maximum tangential attraction force and minimum volume of utilized materials. To form optimal shapes, the points on the clutch surface are chosen as optimization parameters. The optimization is carried out using Ārtap framework in connection with COMSOL software, where the 3D model of the clutch has been created. After the optimization, the tangential attraction force has increased by $13 \%$ and the volume of the clutch has been reduced by $24 \%$. Although the obtained shapes appear to be highly intricate, it does not pose an obstacle for modern manufacturing techniques.
\end{abstract}

Keywords

electromagnetic coupling, optimization, additive manufacturing, Ārtap framework, NSGA-II

\section{Introduction}

The electrical drive systems have an undeniable influence on the energy conservation, environment and sustainable development of the world [1-3]. As an important component of electrical drive systems, Permanent Magnet (PM) clutch always has been an object of research interest.

PM clutches are reliable devices, which can transmit torque in the hazardous environment [4-6]. Extensive implementation of PM clutches is based on their unique features. Particularly, a lack of physical contact between driving and driven member allows transmitting torque over a separator, which is often necessary for biological and food processing applications. Moreover, the friction between the members is eliminated, that helps to avoid mechanical failures, decreases vibration and offers easier maintenance $[7,8]$.
The main issue in PM clutch design is the optimal usage of magnetic and non-magnetic materials. For many years, researchers have successfully applied design optimization to address this issue [9-14]. Most of research works have focused on minimizing the usage of magnetic and non-magnetic materials $[13,14]$. However, linear dimensions have been manly used as optimization parameters due to limited production capacities $[15,16]$. However, manufacturing of geometrically complex objects has become possible employing modern techniques (e.g. additive manufacturing) [17-21]. Therefore, few studies have attempted to obtain more intricate designs. In [22], the authors have searched for optimal shapes of clutch disks using 2D finite element analysis (FEM). However, to find shapes more accurately, it is essential to carry out $3 \mathrm{D}$ design 
optimization. 3D design optimization takes into account the flux distribution all over the body. Consequently, this research optimizes a PM clutch design in 3D intending to obtain a low mass of non-magnetic material and high transmitted torque [23-25].

Besides, this study uses Ārtap framework along with COMSOL to carry out the optimization [26]. Due to high computational complexity, the problem is solved using HPC (High-Performance Computing) with the automatic parallelization functionality of Ārtap. Ārtap [27] is an MIT (Massachusetts Institute of Technology) licensed robust design optimization framework, which provides a user-friendly interface along with a good set of numerical solvers and optimization algorithms. Moreover, using $\bar{A}$ rtap is highly beneficial due to its integrated FEM solver (Agros [28, 29]), and its interconnection with several finite element (FE) solvers (COMSOL and others [27, 30]).

To optimize a PM clutch, this study applies the Nondominated Sorting Genetic Algorithm II (NSGA-II) solver. NSGA-II is a fast sorting and elite multi-objective genetic algorithm, which is becoming a key instrument in the optimization of electrical machines and devices [31, 32]. NSGA-II is highly flexible algorithm, able to find a global minimum and can deal with non-analytic formulation of optimization problems.

\section{Design optimization of the PM clutch}

\subsection{Operation principle of the PM clutch}

This study considered a PM clutch constituted of two components: driving and driven disks with teeth (see Fig. 1). The material of both disks and the driven disk teeth were set as printed steel. The teeth of the driving member of the clutch were Permanent Magnets N52 (Sintered Nd-Fe-B). When the members are coupled, attraction force appears between the magnetic and steel teeth and contains two components: axial force $F_{z}$ and tangential force $F_{t}$. The axial force is a force that attracts clutch members to each other.

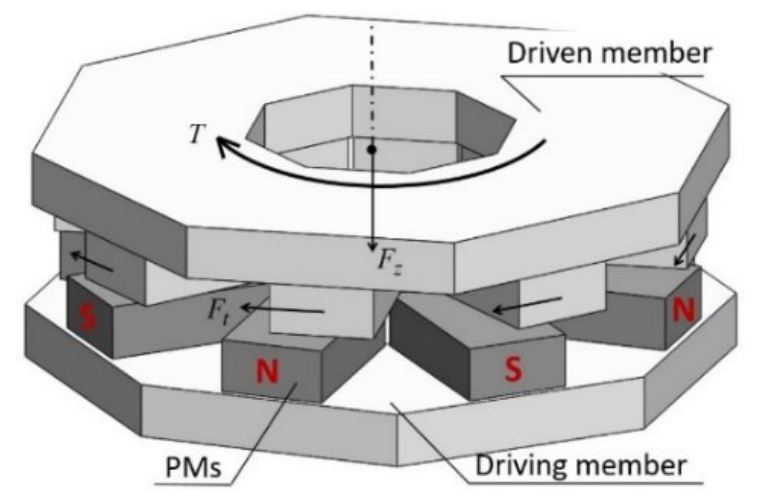

Fig. 1 Initial design of the clutch
The tangential force is a force that tries to align the teeth of the driving and driven member face to face by changing the position of the driven member. This force is associated with the torque being transmitted [33]. The transmitted torque depends on the angle of deviation of the clutch members relative to each other $\delta \theta$, magnetic flux density $B$, and magnetic field intensity $H[4]$ :

$T=\frac{\delta \int_{V} \int_{O}^{\boldsymbol{H}} \boldsymbol{B} d \boldsymbol{H} d V}{\delta \theta}$.

Then, the relation between the torque and tangential force can be expressed by the following equation:

$T=F_{t} \cdot R_{m}$

where $R_{m}$ is the mean radius at which the force acts.

\subsection{Design model of the PM clutch}

The objectives of the PM clutch optimization were maximum tangential attraction force and minimum volume of printed steel material. The optimization started with creating the PM clutch model using COMSOL software. Theclutch disks had eight symmetrical segments. Therefore, only one-eighth of the problem was modelled using periodic boundary conditions. Besides, the clutch was optimized in the position where the angular deflection was equal to $\pi / 16$ and the tangential force reached a maximum (see Fig. 2). In addition, Fig. 2 presents the mesh used in the optimization. The number of elements of the mesh was approximately 50,000. It is important to highlight that the number of elements was changing during optimization. Particularly, the more complex geometry was formed, the more mesh elements were used.

The mathematical model of the clutch in COMSOL was based on the expression:

$-\nabla \cdot\left(\mu \nabla \psi_{m}-\boldsymbol{B}_{r}\right)=0$

where $\psi_{m}$ is the magnetic scalar potential, $\boldsymbol{B}_{r}$ is the remanent magnetic flux density and $\mu$ is the material

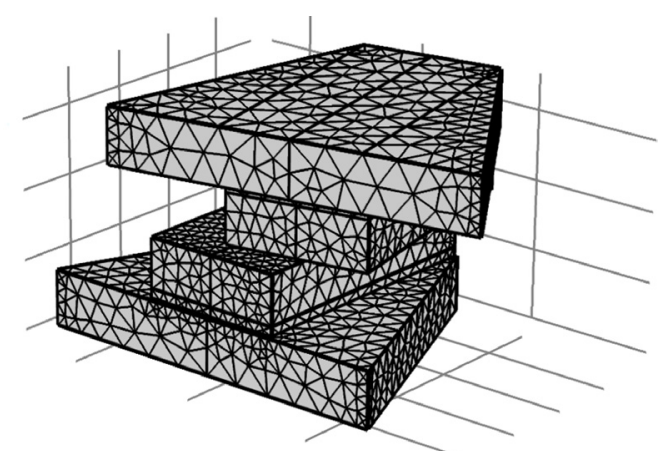

Fig. 2 Meshed design model of the clutch at $\pi / 16$ angular deflection 
permeability. Applying the magnetic scalar potential significantly reduces computational complexity of the design model.

Equation (3) was derived from the following relations:

$\nabla \times-=0 \rightarrow \boldsymbol{H}=-\nabla \psi_{m}, \nabla \cdot \boldsymbol{B}=\nabla \cdot\left(\mu \boldsymbol{H}+\boldsymbol{B}_{r}\right)=0$.

Then, the Maxwell tensor was used to calculate the tangential attraction force.

In order to ensure geometrical continuity and symmetry, the magnetic scalar potential values on one side were set equal to the negative values of the magnetic scalar potential on the other side. Additionally, the mesh was identical on both sides of the one-eighth part of the model.

The utilized printed steel was nonlinear material, which means that its permeability $\pi$ changing with changes in magnetic field intensity (see Fig. 3). The magnetization curve of the printed steel was acquired from a test of a sample [34]. The sample was made of electrical steel with $6.5 \%$ silicon content produced by selective laser melting printing.

The initial geometry of the clutch is shown in Fig. 4. The dimensions of the clutch are reported in Table 1.

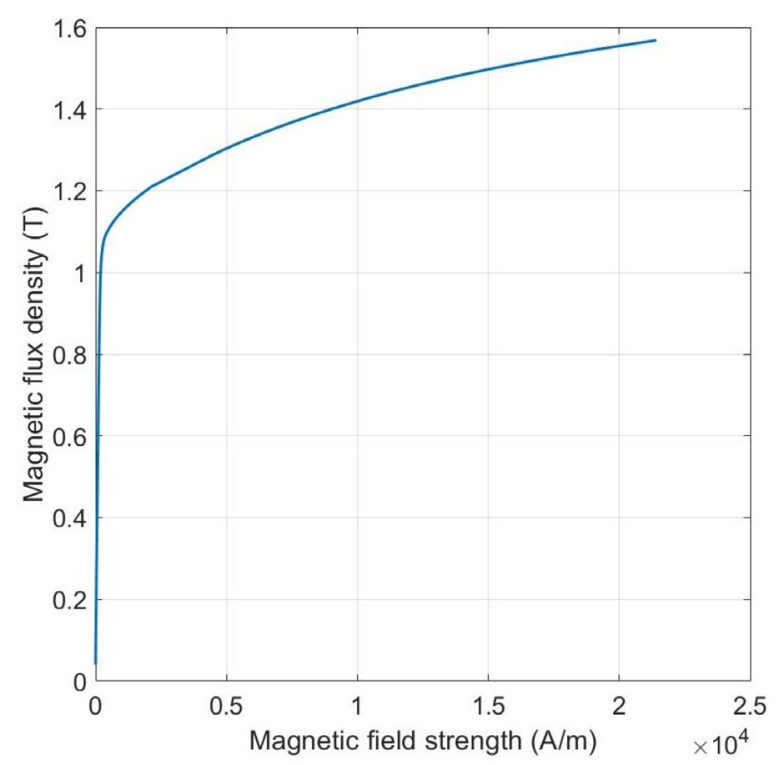

Fig. 3 B-H curve of the printed steel [19]

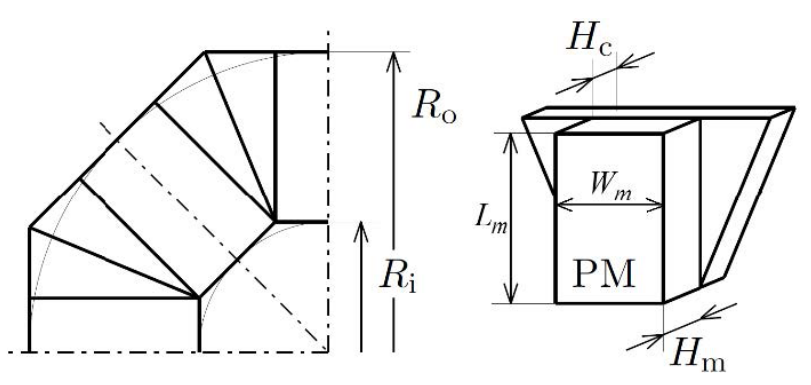

Fig. 4 Geometry of the clutch
Table 1 Clutch dimensions

\begin{tabular}{lc}
\hline Dimension & Value \\
\hline Outer radius $R_{o}$ & $32.5 \mathrm{~mm}$ \\
Inner radius $R_{i}$ & $12.5 \mathrm{~mm}$ \\
Mean radius $R_{m}$ & $21.5 \mathrm{~mm}$ \\
Thickness of the disks $H_{c}$ & $4 \mathrm{~mm}$ \\
Thickness of the magnets & $5 \mathrm{~mm}$ \\
Width of the magnets & $10 \mathrm{~mm}$ \\
Length of the magnets & $18 \mathrm{~mm}$ \\
Air gap & $1 \mathrm{~mm}$ \\
\hline
\end{tabular}

\subsection{Optimization parameters}

The optimization model had 56 parameters, which are presented in Fig. 5. The parameters, which correspond to the points located on the disk end faces are marked with red. The parameters, which correspond to the points located on the teeth end faces are marked with green. During optimization, the points could move in $z$-direction within the following limits: red points' limits were $[0,1.5] \mathrm{mm}$, green points' limits were $[0,4.5]$. Both clutch members had the same parametrization. However, the shapes and sizes of the magnetic teeth were fixed.

\subsection{Solving the optimization problem in Ārtap}

The optimization was carried out using two interconnected programs: Ārtap and COMSOL. Within Ārtap, optimization algorithm NSGA-II was implemented, while the values of objective functions were calculated in COMSOL.

Formulation of the current optimization problem in Ārtap environment is shown in Algorithm 1. The optimization objectives and parameters were defined in the "ComsolProblem" class. The values of the objective functions were generated by COMSOL in the file named "OUT.txt".

When the problem was defined, the optimization algorithm and its setting were specified in the "solve" function (see Algorithm 2).
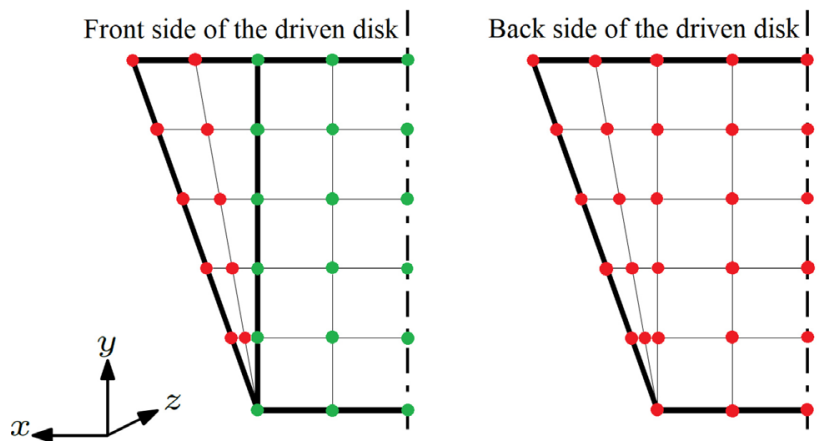

Fig. 5 Parametrization of the clutch model 

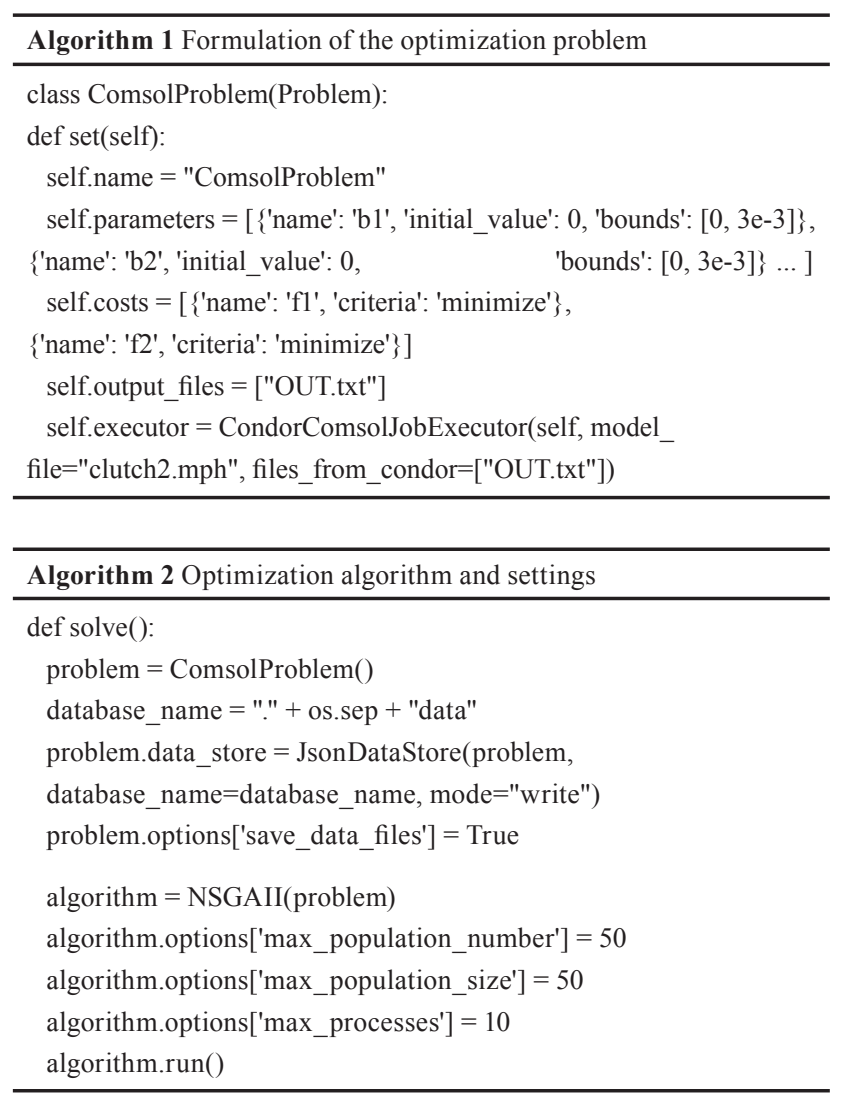

In this study, NSGA-II optimization algorithm was used due to its high efficiency and reliability. For NSGA-II, the settings were the following: number of generations and number of individuals in each generation. The number of individuals, as well as the number of generations, was 50, which led to 2,500 calculations. Additionally, the maximum number of parallel processes was defined to 10 , since the computing cluster "Condor" was used.

\section{Results}

The results of the optimization are reported in the objectives plane in Fig. 6, together with the Pareto front. It can be noticed that the solutions converge to the optimal ones, which are located close to the left corner of the plot. The Pareto front is steep as long as the volume has variations around close values of the tangential attraction force. Overall, Fig. 6 confirms that the PM clutch is able to compromise a low volume with a high tangential attraction force.

Fig. 7 shows the magnetic flux density of the optimized clutch, while Fig. 8 presents the optimized shapes of the clutch in detail.

Interestingly, Fig. 7 shows quite low magnetic flux density of the optimized clutch on the bottom of driving and driven disks. A possible explanation for this might be that the limits defined for the changes of optimization parameters were too small.

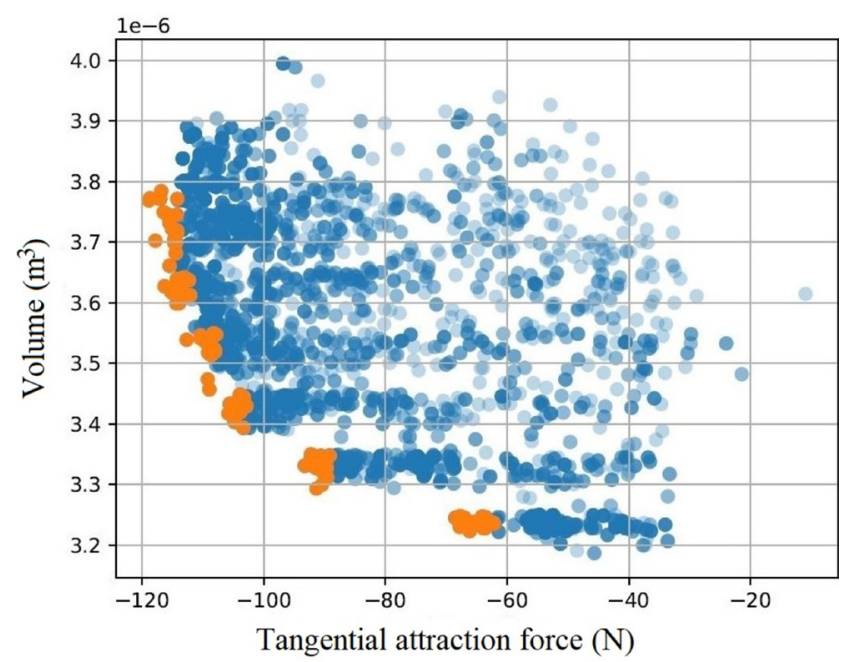

Fig. 6 Simulated individuals in the objective plane and Pareto front

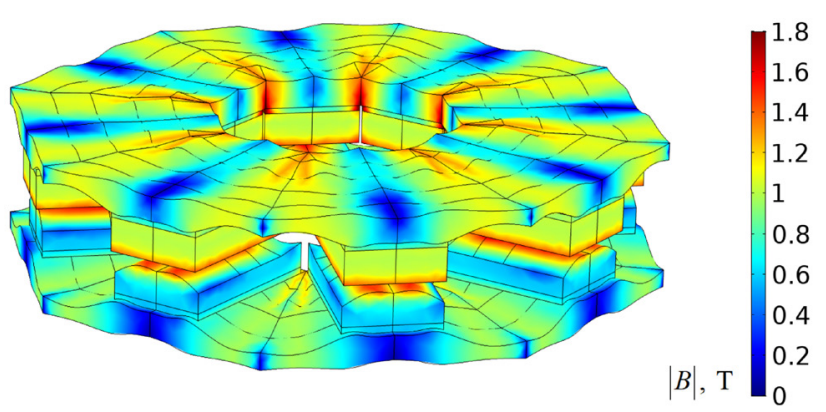

Fig. 7 Magnetic flux density of the optimized PM clutch

Table 2 illustrates the comparison of initial and optimized design in terms of the volume and tangential attraction force. From Table 2 it can be concluded, the tangential attraction force increased by $13 \%$ and the volume was reduced by $24 \%$.

\section{Conclusions}

The current research aimed to optimize a PM clutch to achieve high transmitted torque and low volume of steel material.

After the optimization with 2,500 calculations, the volume was reduced and the tangential force increased significantly. It is worth mentioning that the intricacy of the obtained shapes of the clutch does not pose a big obstacle since modern manufacturing techniques such as additive manufacturing allow producing complex geometries [17, 34]. Nevertheless, additive manufacturing may possess several issues: geometrical imperfections and inaccuracy in material properties, which can have a negative influence on the efficient work of the clutch $[9,35]$. To ensure the accuracy of geometry and material properties, robust optimization can be applied. For this purpose, further research might focus on robust optimization of the PM clutch. 

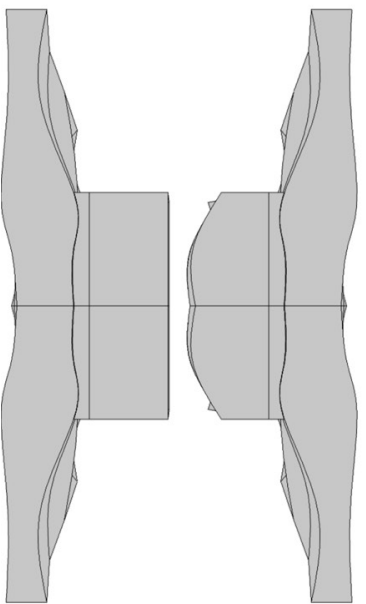

(a)

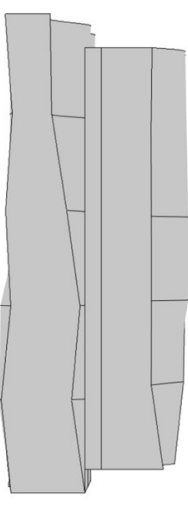

(b)

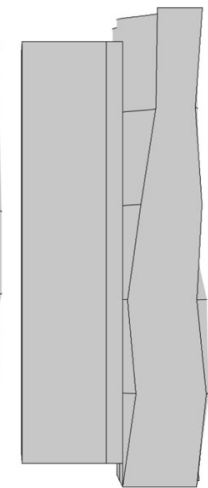

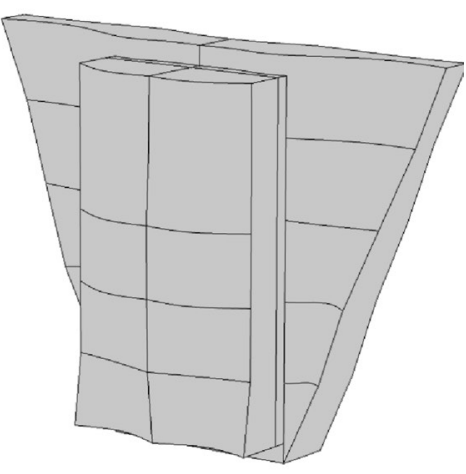

(c)

Fig. 8 Optimized shapes of the PM clutch: (a) top view of the clutch, (b) side view of the clutch, (c) driven disk

Table 2 Comparison of initial and optimal design

\begin{tabular}{lcc}
\hline Objective & Initial design & Optimal design \\
\hline Volume & $4.6 \cdot 10^{-6} \mathrm{~m}^{3}$ & $3.5 \cdot 10^{-6} \mathrm{~m}^{3}$ \\
$\begin{array}{l}\text { Maximum tangential } \\
\text { attraction force } F_{t}\end{array}$ & $97 \mathrm{~N}$ & $110 \mathrm{~N}$ \\
$\begin{array}{l}\text { Maximum axial } \\
\text { attraction force } F_{t}\end{array}$ & $1056 \mathrm{~N}$ & $732 \mathrm{~N}$ \\
Torque $T$ & $2.09 \mathrm{Nm}$ & $2.37 \mathrm{Nm}$ \\
\hline
\end{tabular}

\section{References}

[1] Heidari, H., Rassõlkin, A., Vaimann, T., Kallaste, A., Taheri, A., Holakooie, M. H., Belahcen, A. "A Novel Vector Control Strategy for a Six-Phase Induction Motor with Low Torque Ripples and Harmonic Currents", Energies, 12(6), Article No. 1102, 2019. https://doi.org/10.3390/en12061102

[2] Rassõlkin, A., Belahcen, A., Kallaste, A., Vaimann, T., Lukichev, D. V., Orlova, S., Heidari, H., Asad, B., Acedo, J. P. "Life cycle analysis of electrical motor drive system based on electrical machine type", Proceedings of the Estonian Academy of Sciences, 69(2), pp. 162-177, 2020.

https://doi.org/10.3176/proc.2020.2.07

[3] Vaimann, T., Kallaste, A., Bolgov, V., Belahcen, A. "Environmental considerations in lifecycle based optimization of electrical machines", In: 2015 16th International Scientific Conference on Electric Power Engineering, Kouty nad Desnou, Czech Republic, 2015, pp. 209-214.

https://doi.org/10.1109/EPE.2015.7161057

[4] Ferreira, C., Vaidya, J. "Torque analysis of permanent magnet coupling using $2 \mathrm{~d}$ and $3 \mathrm{~d}$ finite elements methods", IEEE Transactions on Magnetics, 25(4), pp. 3080-3082, 1989.

https://doi.org/10.1109/20.34375

[5] Ravaud, R., Lemarquand, V., Lemarquand, G. "Analytical design of permanent magnet radial couplings", IEEE Transactions on Magnetics, 46(11), pp. 3860-3865, 2010. https://doi.org/10.1109/TMAG.2010.2056379
Besides, design optimization models, calculations and results can be downloaded from the homepage of the project [36].

\section{Acknowledgment}

The research was supported by the Estonian Research Council under grant PSG137 "Additive Manufacturing of Electrical Machines".

[6] Wang, Y., Filippini, M., Bianchi, N., Alotto, P. "A Review on Magnetic Gears: Topologies, Computational Models, and Design Aspects", IEEE Transactions on Industry Applications, 55(5), pp. 4557-4566, 2019. https://doi.org/10.1109/TIA.2019.2916765

[7] Overshott, K. J. "The comparison of the pull-out torque of permanent magnet couplings predicted theoretically with experimental measurements", IEEE Transactions on Magnetics, 25(5), pp. 3913-3915, 1989.

https://doi.org/10.1109/20.42475

[8] Weinmann, D., Wiesmann, H. J. "Application of rare earth magnets to coaxial synchronous couplings", Journal of Magnetism and Magnetic Materials, 9(1-3), pp. 179-181, 1978.

https://doi.org/10.1016/0304-8853(78)90047-1

[9] Lei, G., Zhu, J., Guo, Y., Liu, C., Ma, B. "A review of design optimization methods for electrical machines", Energies, 10(12), Article No. 1962, 2017.

https://doi.org/10.3390/en10121962

[10] Duan, Y., Ionel, D. M. "A review of recent developments in electrical machine design optimization methods with a permanent magnet synchronous motor benchmark study", In: IEEE Energy Conversion Congress and Exposition: Energy Conversion Innovation for a Clean Energy Future, Phoenix, AZ, USA, 2011, pp. 3694-3701.

https://doi.org/10.1109/ECCE.2011.6064270 
[11] Pabut, O., Eerme, M., Kallaste, A., Vaimann, T. "Multi-criteria design optimization of ultra large diameter permanent magnet generator", Elektronika ir Elektrotechnika, 21(3), pp. 42-48, 2015. https://doi.org/10.5755/j01.eee.21.3.10278

[12] Wang, A., Wang, J., Wu, B., Shi, C. "Structural optimization of the permanent magnet drive based on artificial neural network and particle swarm optimization", In: 2011 3rd International Conference on Intelligent Human-Machine Systems and Cybernetics, Hangzhou, China, 2011, pp. 70-74. https://doi.org/10.1109/IHMSC.2011.87

[13] El-Wakeel, A. S. "Design optimization of PM couplings using hybrid Particle Swarm Optimization-Simplex Method (PSO-SM) Algorithm", Electric Power Systems Research, 116, pp. 29-35, 2014. https://doi.org/10.1016/j.epsr.2014.05.003

[14] Zhang, B., Wan, Y., Li, Y., Feng, G. "Optimized design research on adjustable-speed permanent magnet coupling", In: IEEE International Conference on Industrial Technology, Cape Town, South Africa, 2013, pp. 380-385. https://doi.org/10.1109/ICIT.2013.6505702

[15] Wu, W., Lovatt, H. C., Dunlop, J. B. "Analysis and design optimisation of magnetic couplings using 3D finite element modelling", IEEE Transactions on Magnetics, 33(5), pp. 4083-4085, 1997. https://doi.org/10.1109/20.619670

[16] Eliès, P., Lemarquand, G. "Analytical optimization of the torque of a permanent-magnet coaxial synchronous coupling", IEEE Transactions on Magnetics, 34(4), pp. 2267-2273, 1998. https://doi.org/10.1109/20.703865

[17] Frazier, W. E. "Metal additive manufacturing: A review", Journal of Materials Engineering and Performance, 23(6), pp. 1917-1928, 2014. https://doi.org/10.1007/s11665-014-0958-z

[18] Johnson, K., Zemba, M., Conner, B. P., Walker, J., Burden, E., Rogers, K., Cwiok, K. R., Macdonald, E., Cortes, P. "Digital Manufacturing of Pathologically-Complex 3D Printed Antennas", IEEE Access, 7, pp. 39378-39389, 2019. https://doi.org/10.1109/ACCESS.2019.2906868

[19] Kruth, J. P., Leu, M. C., Nakagawa, T. "Progress in additive manufacturing and rapid prototyping", CIRP Annals - Manufacturing Technologies, 47(2), pp. 525-540, 1998. https://doi.org/10.1016/S0007-8506(07)63240-5

[20] Keresztes, Z., Pammer, D., Szabo, J. P. "EBSD examination of argon ion bombarded Ti-6Al-4V samples produced with DMLS technology", Periodica Polytechnica Mechanical Engineering, 63(3), pp. 195-200, 2019. https://doi.org/10.3311/PPme.13821

[21] Tiismus, H., Kallaste, A., Rassõlkin, A., Vaimann, T. "Preliminary Analysis of Soft Magnetic Material Properties for Additive Manufacturing of Electrical Machines", Key Engineering Materials, 799, pp. 270-275, 2019.

https://doi.org/10.4028/www.scientific.net/KEM.799.270

[22] Andriushchenko, E. A., Kallaste, A., Belahcen, A., Heidari, H., Vaimann, T., Rassõlkin, A. "Design Optimization of Permanent Magnet Clutch", In: 2020 International Conference on Electrical Machines, Gothenburg, Sweden, 2020.

https://doi.org/10.1109/ICEM49940.2020.9270726
[23] Lubin, T., Fontchastagner, J., Mezani, S., Rezzoug, A. "Comparison of transient performances for synchronous and eddy-current torque couplers", In: 2016 22nd International Conference on Electrical Machines (ICEM), Lausanne, Switzerland, 2016, pp. 695-701. https://doi.org/10.1109/ICELMACH.2016.7732602

[24] Zerioul, A., Hadjout, L., Ouazir, Y., Bensaidane, H., Benbekai, A., Chaouch, O. "3D Analytical Model to Compute the Electromagnetic Torque of Axial Flux Magnetic Coupler with A Rectangular-Shaped Magnet", In: 2018 3rd International Conference on Electrical Sciences and Technologies in Maghreb, Algiers, Algeria, 2019. https://doi.org/10.1109/CISTEM.2018.8613547

[25] Meng, Z., Lu, W., Meng, Z., Sun, Y., Zhu, H. "Research on modelling and simulation for dynamic characteristics of magnetic shaft coupling", International Journal of Engineering Systems Modelling and Simulation, 9(2), pp. 78-85, 2017. https://doi.org/10.1504/IJESMS.2017.083226

[26] Kaska, J., Orosz, T., Karban, P., Dolezel, I., Pechanek, R., Panek, D., "Optimization of Reluctance Motor with Printed Rotor", In: 22nd International Conference on the Computation of Electromagnetic Fields, Paris, France, 2019. https://doi.org/10.1109/COMPUMAG45669.2019.9032792

[27] Panek, D., Orosz, T., Karban, P. "Artap: Robust Design Optimization Framework for Engineering Applications", In: 2019 3rd International Conference on Intelligent Computing in Data Sciences, Marrakech, Morocco, 2019. https://doi.org/10.1109/ICDS47004.2019.8942318

[28] Pánek, D., Karban, P., Orosz, T., Doležel, I. "Comparison of simplified techniques for solving selected coupled electroheat problems", International Journal for Computation and Mathematics in Electrical and Electronic Engineering, 39( 1), pp. 220-230, 2020. https://doi.org/10.1108/COMPEL-06-2019-0244

[29] Karban, P., Pánek, D., Orosz, T., Petrášová, I., Doležel, I. "FEM based robust design optimization with Agros and Ārtap", Computers and Mathematics with Applications, 81, pp. 618-633, 2021. https://doi.org/10.1016/j.camwa.2020.02.010

[30] Karban, P., Panek, D., Orosz, T., Doležel, I. "Semi-analytical Solution for a Multi-objective TEAM Benchmark Problem", Periodica Polytechnica Engineering and Computer Science, 2020.

[31] Deb, K., Pratap, A., Agarwal, S., Meyarivan, T. "A fast and elitist multiobjective genetic algorithm: NSGA-II", IEEE Transactions on Evolutionary Computation, 6(2), pp. 182-197, 2002. https://doi.org/10.1109/4235.996017

[32] Coello Coello, C. A., Lamont, G. B., Van Veldhuizen, D. A. "Evolutionary Algorithms for Solving Multi-Objective Problems", Springer, New York. NY, USA, 2007. https://doi.org/10.1007/978-0-387-36797-2

[33] Tong, W. "Mechanical Design of Electric Motors", CRC Press, Boca Raton, FL, USA, 2014. https://doi.org/10.1201/b16863

[34] Tiismus, H., Kallaste, A., Vaimann, T., Rassolkin, A., Belahcen, A. "Axial Synchronous Magnetic Coupling Modeling and Printing with Selective Laser Melting", presented at 2019 IEEE 60th International Scientific Conference on Power and Electrical Engineering of Riga Technical University, Riga, Latvia, Oct, 7-9, 2019. https://doi.org/10.1109/RTUCON48111.2019.8982344 
[35] Buchanan, C., Gardner, L. "Metal 3D printing in construction: A review of methods, research, applications, opportunities and challenges", Engineering Structures, 180, pp. 332-348, 2019. https://doi.org/10.1016/j.engstruct.2018.11.045
[36] Orosz, T. "Artap", [online] Available at: https://github.com/artapframework/artap/tree/master/examples/Problems $\% 20$ from $\% 20$ PP\%20special\%20issue [Accessed: 08 August 2020] 